\title{
EFFECT OF BONDING AGENTS ON THE BOND STRENGTH BETWEEN DIFFERENT POSTS AND CORE MATERIALS
}

\author{
Ashraf I Abusaif*, Ahmed Y El Kouedi** and Tamer A Hamza ${ }^{* * *}$
}

\begin{abstract}
Statement of problem: There are many different types of adhesive systems available on the market for the dentist to use. Debonding of core material is still considered a common type of failure. The successful interaction between the dowels, core material and bonding system is still a concern. Aim of study: The aim of this study was to compare the effect of bonding agents on the bond strength between different dowels and core materials Result: Three way-ANOVA showed a significant effect on mean push out bond strength at $\mathrm{p} \leq 0.05$. The Tukey honestly significant difference (HSD) test showed that composite core material exhibit highly significant push out bond strength than other core material used in this study. The results of this study also showed that samples with no bond had the lowest bond strength followed by self etch and the highest one was with total etch which was statistically significant.
\end{abstract}

\section{INTRODUCTION}

Restoring endodontically treated teeth remains one of the most challenging problems facing the restorative dentist. It is well known that endodontically treated teeth are more prone to fracture than vital teeth $^{(1)}$.

A badly mutilated teeth in the present conservative era, needs to be restored with a post and core. The primary functions of the post are to distribute load by dispersing it along the long axis of the tooth and to provide retention for the core that supports the final crown ${ }^{(2)}$.

Posts in the past were either cast or prefabricated metal and primarily provide means for attachment of the core to the remaining tooth structure.

Invitro research has indicated that fracture resistance of teeth restored with prefabricated metallic posts was higher than that of teeth restored with cast metal posts ${ }^{(3)}$.
Currently, there is a range of nonmetallic posts available. Some are made of a resin matrix reinforced with carbon, glass, or quartz fibers, whereas others are made of ceramic materials. Tooth-colored posts are believed to result in improved esthetics when used for anterior teeth to be restored with all-ceramic crowns, and some of these posts have modulus of elasticity values that approximate that of dentin and are believed to help prevent root fracture ${ }^{(3)}$.

In the last few decades, cast posts have been the most commonly used form of restoration for these teeth. Unfortunately, several disadvantages associated with conventional cast post-and-cores have been reported, such as loss of retention of the post, a potential for post and root fracture, and a risk of corrosion when different metals were used ${ }^{(4-6)}$.

Recently, the use of fiber-reinforced composite posts has increased due to their good biomechanical compatibility with dentin, which produces more favorable stress distribution, decreases

\footnotetext{
* Dentist, Ministry of Health.

** Associate Professor, Crown and Bridge Department, Faculty of Dental Medicine Azhar University (Cairo, Boys) *** Professor, Crown and Bridge Department, Faculty of Dental Medicine Azhar University (Cairo, Boys)
} 
the occurrence of root fractures in general and decreases the risk of catastrophic root fracture. Unlike metallic posts, the most frequent failure of fiber post restoration was not due to fracture, but to debonding, which may occur between fiber post and resin or between resin and intraradicular dentin. However, it should be noted that a reliable bond between fiber post and core resin also plays an important role in the post-core restoration of endodontically treated teeth ${ }^{(7)}$.

Monticelli et al ${ }^{(8)}$ searched improvement of adhesion in dowel/core restorations using five different chemical surface treatments and two composite materials to build-up the abutment. They found that etching procedures showed a similar effect on the dowel-surface and enhanced the adhesion of composite core build-ups as a result of micromechanical and chemical retention.

Kurt et al researched the effects of different surface treatments on the bond strength of glass fiber-reinforced composite root canal dowels to composite core material. They found that the lowest bond strength was observed in the Er: YAG 500$\mathrm{mJ}$ group. The acid-etched group revealed a higher bond strength that the control group. The highest bond strength was observed in the airborne-particle abrasion group ${ }^{(9)}$.

Mosharraf and Yazdi made a comparative evaluation of effects of different surface treatment methods on bond strength between fiber dowel and composite core. They conclude that there was not any significant difference between two brands of fiber dowels that had been used in this study. Although silanization and sandblasting can improve the tensile bond strength, there were not any significant differences between surface treatments used $^{(10)}$.

The choice of appropriate restorations for these teeth that are endodontically treated and are badly decayed is guided by strength and esthetics. Alternatives to cast dowels and cores have been developed. The use of prefabricated dowel and custom-made buildups with direct core materials simplifies the restorative procedure because all steps can be completed chair side and fair clinical success can be expected ${ }^{(11)}$.

Direct core materials consist of amalgam, composite resin and glass ionomers (GI). The GI category can be further broken down into resin-modified glass ionomers (RMGI), metal-modified glass ionomers (MMGI), compomers and ceramets ${ }^{(12)}$.

Silver amalgam demonstrated high compressive strength and rigidity. Traditionally, the ability of glass ionomers to bond to enamel and dentin and to release fluoride was the reason clinicians favored these over amalgams. Recently, conventional glass ionomers have been improved by a higher powderto-liquid ratio, thereby requiring less water. Glass particle sizes are also smaller, resulting in higher viscosity. Some studies do not recommend use of glass-ionomer-based materials as core materials because they are weaker than other alternations ${ }^{(10)}$.

Direct resin composite materials allow the clinician to perform core build-up and crown preparation procedures in one visit. Their ease of use and rapid curing has resulted in a dramatic growth in their use ${ }^{(13)}$.

\section{MATERIALS AND METHODS}

A total of 180 dowels were divided into three equal main groups of 60 samples each according to the type of the bond used a total etch Tetric $\mathrm{N}$ bond group $\{\mathrm{T}\}$, Tetric $\mathrm{N}$ bond self-etch $\{\mathrm{S}\}$ and control group with no bond used $\{\mathrm{N}\}$. Each group of the three main groups was divided into two equal subgroups of 30 samples each according to the type of the used dowel (metal and glass fiber). Finally, each subgroup was divided into three equal subgroups of 10 samples according to the type of core material (amalgam, composite and resin reinforced glass ionomer). Standardized dowel and core samples were constructed using a specially designed constructed split brass mold figure (1). 
There were two different molds were machined, one with dowel space length $7.5 \mathrm{ml}$ for metal dowel \&another with $15 \mathrm{ml}$ in length for glass fiber dowel. A stabilizing ring was machined for stabilizing the assembled mold.

The dowel was cleaned with $70 \%$ ethyl alcohol and left to air dry on a clean glass slab. When glass fiber dowel was used it was coated with two layers of silane coupling agent and left to dry on a clean glass slab according to manufacturer's instructions.

$\mathbf{S}$ and $\mathbf{T}$ groups construction the dowel was held with a tweezer and inserted into the dowel channel with a vertical force until it was seated to its full depth. The dowel surface was painted with two layers of the bonding agent and dried with oil free and moisture free compressed air, and then it exposed to light cure ${ }^{1}$ for 20 seconds according to manufacturer's instructions.

N group construction: The dowel was held with a tweezer and inserted into the dowel channel with a vertical force until it was seated to its full depth. The core material is applied directly without application of the bonding agent as in $\mathrm{T}$ and $\mathrm{S}$ groups to form the dowel-core combination.

After fabrication of samples through special teffelon model, all samples were embedded in acrylic resin before sawing through IsoMet microsaw to form a slice of $2 \mathrm{~mm}$ to be ready for testing by universal testing machine figure (2).
Each acrylic embedded dowel core combination slice was secured in a custom-made loading fixture. Then subjected to compressive loading $5(\mathrm{k} \mathrm{n})$ at a crosshead speed of $1 \mathrm{~mm} / \mathrm{min}$ via a computercontrolled material testing machine.

Scanning electron microscope (SEM) photography was done for a representative sample for each group to determine the mode of failure.

\section{RESULTS}

Three way-ANOVA shows that different core material, bond and dowel, all showed a significant effect on mean push out bond strength at $\mathrm{p} \leq 0.05$.

The Tukey honestly significant difference (HSD) test showed that composite core material exhibit highly significant push out bond strength than other core material used in this study. The results of this study also showed that samples with no bond had the lowest bond strength followed by self etch and the highest one was with total etch which was statistically significant. In amalgam and composite groups, the glass fiber was significantly higher than stainless-steel. This was statistically significant. As shown in figure (3)

\section{Result of SEM photographs:}

Randomly selected samples were taken from the different subgroups and examined under a scanning electron microscope SEM. The SEM result obtained from the interface between dowel and core materials after testing clarified in figures $(4,5,6)$.

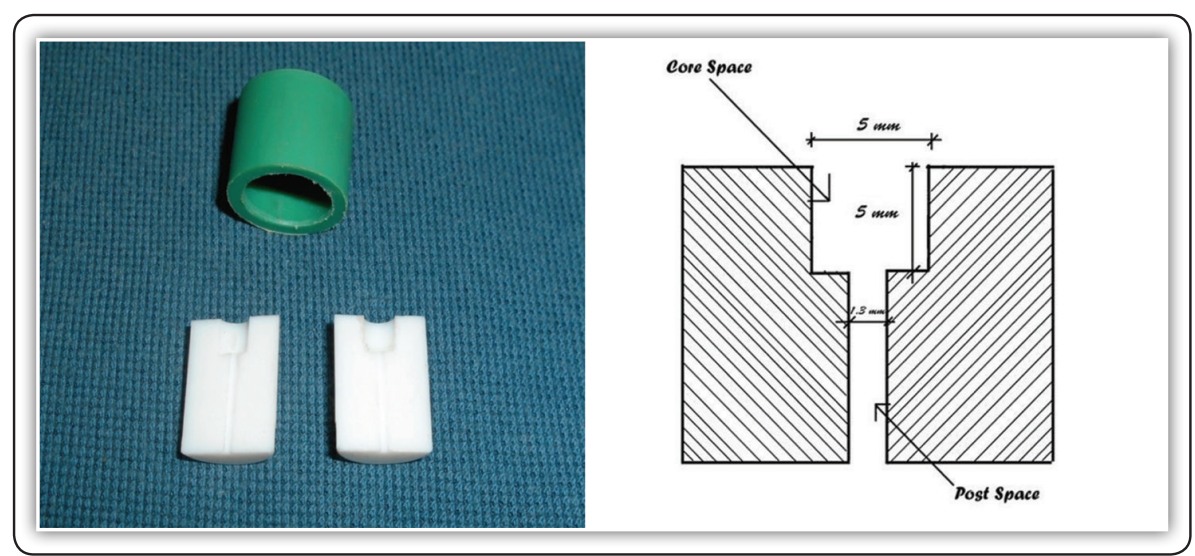

FIG (1) Splitted tefflon mold with descriptive diagram of the mold with measurements 


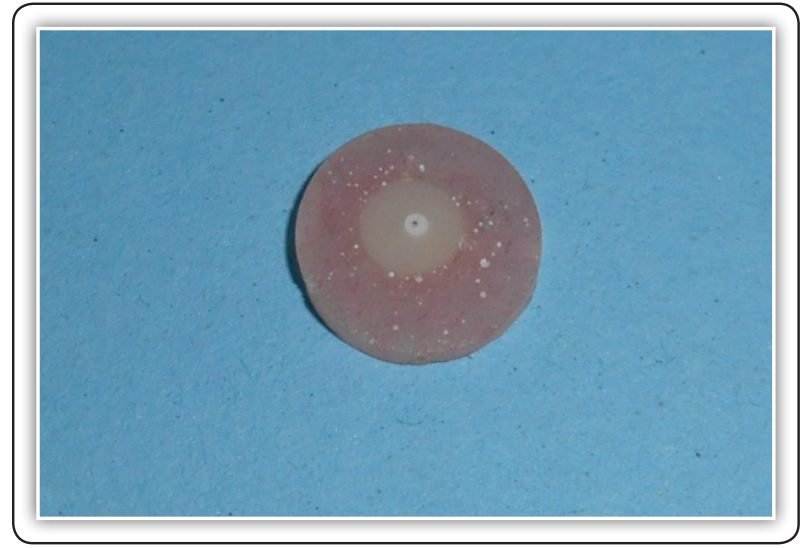

FIG (2) Sample section

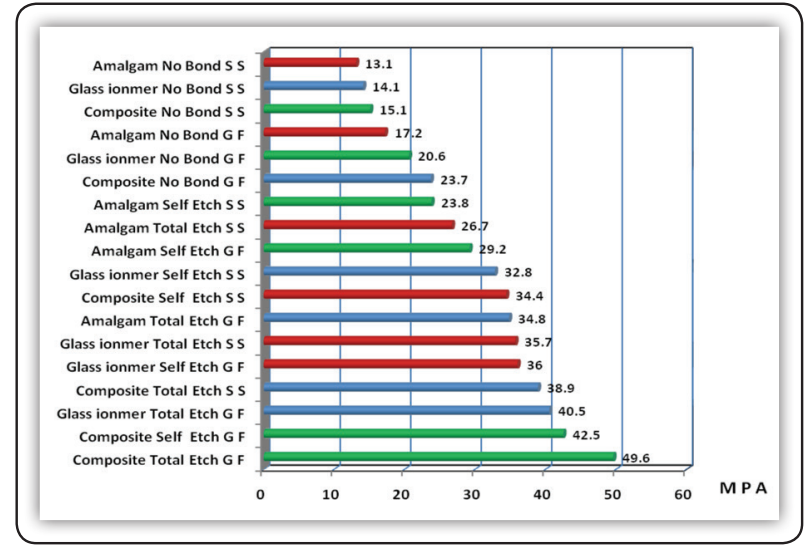

FIG (3) Mean bond strength (MPa)

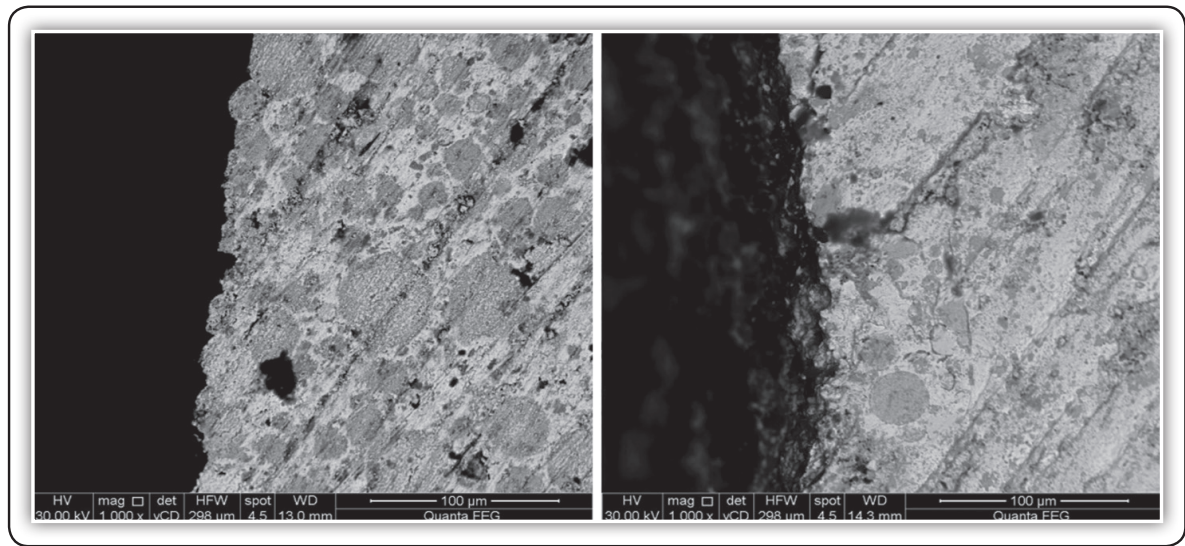

FIG (4) Samples without bonding agent (N group) $\{1000 x\}$ showing intact core surface

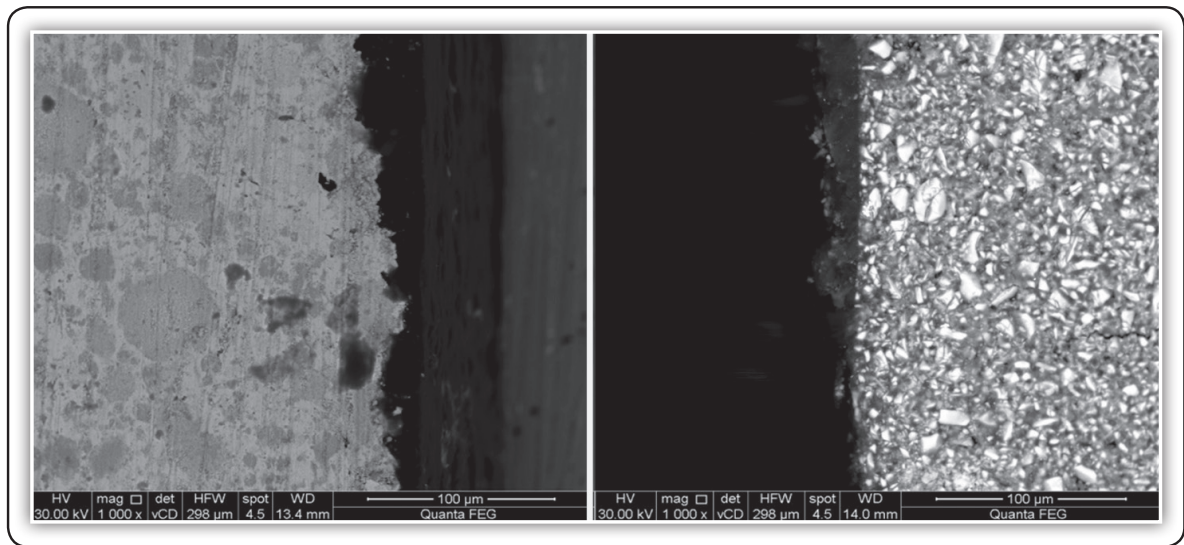

FIG (5) Samples of metal dowels (S group) (T group) $\{1000 \mathrm{x}\}$ showing adhesive failure of bonding agent from dowel surface 


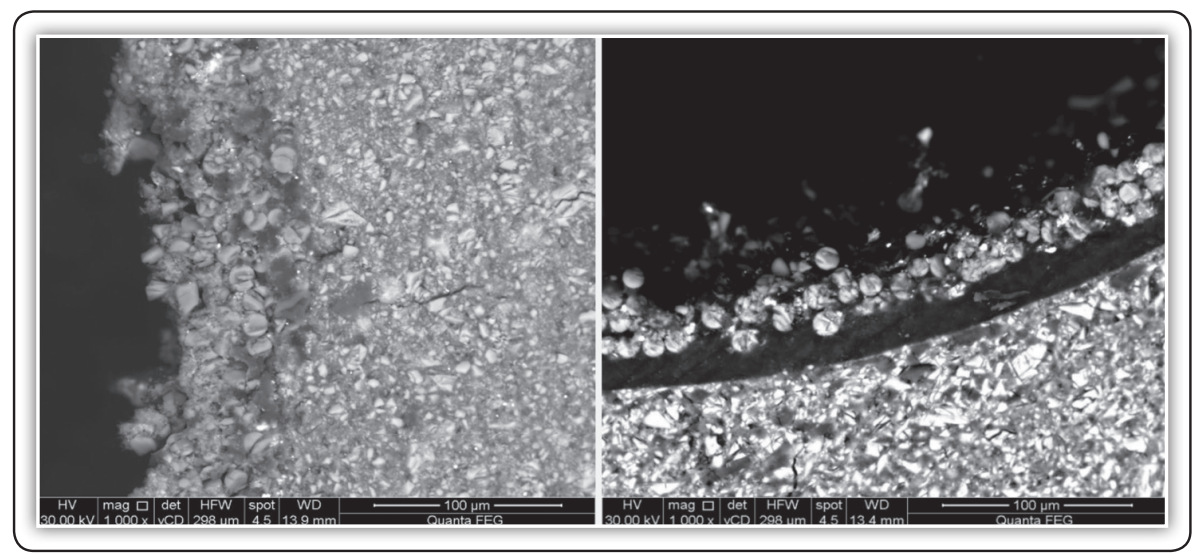

FIG (6) Samples of glass fiber dowels (S group) (T group) $\{1000 x\}$ showing glass fiber detached from dowel and adhered to core surface

\section{DISCUSSION}

The hypothesis of this study that was applying bonding agent to the surface of dowel will increase the bond between the dowel and core material was accepted.

The results of this study showed that composite core material exhibit highly significant push out bond strength than other core material used in this study.

This result was in agreement with Ling Zang et $\mathrm{al}^{(7)}$, Montacilli et $\mathrm{al}^{(15)}$ and Markovic et $\mathrm{al}^{(16)}$.

The explanation of this result may be due to its low viscosity that exhibit excellent adaptability to the dowel surface.

Samples fabricated with stainless-steel dowels were lower in bond strength than glass fiber dowels. This can be explained easily as silanization of glass fiber dowel surface which is a manufacture recommendation appear to be the mean cause of that result. Also, the surface roughness of the glass fiber dowel plays an important role in increasing bonding strength.

SEM photos support this result as there is a cohesive failure in glass fiber dowel as some fibers detached from dowel and attached to the core, while there was an adhesive failure with metal dowel.
Many authors were in agreement with this result as surface treatment with silane and roughness of glass fiber dowel surface increase the bonding strength between dowel and composite resin $\sin ^{(6,717-21)}$.

The results of this study showed that samples with no bond had the lowest bond strength followed by self etch and the highest one was with total etch which was statistically significant. This can be explained as the both types of bonding agents used in this study include phosphate ester in its content which is the main component of MDP.

The total etch group bonding strength was higher than self etch one as it contains HEMA which is a versatile low molecular weight hydrophilic monomer. The hydrophilicity of HEMA makes it an excellent adhesion-promoting monomer. HEMA is frequently added to adhesives, not only to ensure good wetting, but also because of its solvent-like nature. This improves stability and helps keep hydrophobic and hydrophilic monomers in solution by minimizing phase separation in the presence of water ${ }^{(22)}$.

This result was in agreement with Aksornmuang et al ${ }^{(19,20)}$ and Fernanda Tranchesi Sadek ${ }^{(21)}$. They said that applying bonding agent to the dowel surface improve the adhesion of composite resins to fiber dowels, which is related to the chemical composition, viscosity of a bonding agent, compatibility between resin cement and dowel matrix and surface roughness. 
Within the limitations of this study, it can be concluded that:

1. Using glass fiber dowel provides higher bond strength than a metal one regardless the bond type or core material type.

2. Using composite core material regardless the bond type provides higher bond strength than other types of core materials.

3. The application of total etch bond on the surface of the dowel provide higher bond strength than the self-adhesive system with all types of cores used in this study.

\section{REFERENCES}

1. Hurmuzlu F et al. Fracture resistance of endodontically treated premolars restored with ormocer and packable composite. J Endod, 2003. 29(12): 838-40.

2. Sethuraman R. The effect of three post and core systems on the stress distribution in endodontically treated teethA two-dimensional finite element analysis. J Adv Dental Research 2011. II(I): 41-50.

3. Coelho Santos G Jr., O El-Mowafy and JH Rubo. Diametral tensile strength of a resin composite core with nonmetallic prefabricated posts: an in vitro study. J Prosthet Dent, 2004. 91(4): 335-41.

4. Vichi A, Grandini S, and Ferrari M. Comparison between two clinical procedures for bonding fiber posts into a root canal: A Microscopic Investigation. J Endodontics 2002. 28: 355-60.

5. Morgano SM. Restoration of pulpless teeth: application of traditional principles in present and future contexts. $\mathrm{J}$ Prosthet Dent, 1996; 75:375-380.

6. Stockton LW. Factors affecting retention of post systems: a literature review. J Prosthet Dent, 1999;81: 380-385.

7. Zhang L, Wang Y, Radovic I, Chieffi N, Chen J, Ferrari M: Adhesion of two dual-cure core resins to silica fiber posts treated with different bonding agents. J Int Dent 2010;5(3):70-79.

8. Francesca Monticellia, Manuel Toledanob, Franklin R. Tayc, Alvaro H. Curya, Cecilia Goraccia, Marco Ferraria, Post-surface conditioning improves interfacial adhesion in post/core restorations. J Dent Mater, 2006; 22: 602-9.

9. Murat Kurt, Ahmet Umut Güler, _Ibrahim Duran, Altay Uludamar, Ozgu“ r_Inan Effects of different surface treat- ments on the bond strength of glass fiber-reinforced composite root canal posts to composite core material. J Dent Sci, 2012; 7: 20-5.

10. Ramin Mosharraf1, Najmeh Baghaei Yazdi, Comparative evaluation of effects of different surface treatment methods on bond strength between fiber post and composite core. J Adv Prosthodont, 2012. 4: 103-8.

11. Heydecke G, Hussein A, Strub JR., Fracture strength after dynamic loading of endodontically treated teeth restored with different post-and-core systems. J Prosthet Dent, 2002; 87: 438-45

12. Idhu SK, Watson TF. Resin-modified glass ionomer materials. A status report for the American Journal of Dentistry. Am J Dent. 1995; 8:59-67.

13. Craig RG. Direct esthetic restorative materials. In Restorative Dental Materials, 10th ed. St Louis: Mosby, 1997:244-80.

14. Chutinan S, Platt JA, Cochran MA, Moore BK. Volumetric dimensional change of six direct core materials. Dent Mater. 2004; 20(4):345-51.

15. Monticelli F, Goracci C, Grandini S, Garcia-Godoy F, Ferrari M. Scanning electron microscopic evaluation of fiber post-resin core units built up with different resin composites. Am J Dent 2005; 18: 61-5.

16. Boschian PL, Cavalli G, Bertani P, Gagliani M. Adhesive post endodontic restorations with fiber posts: push-out tests and SEM observations. Dent Mater 2002; 18:596-602.

17. Barghi N, Berry T, Chung K. Effects of timing and heat treatment of silanated porcelain on the bond strength. $\mathrm{J}$ Oral Rehabil 2000; 27: 407-12.

18. Pape PG, Plueddemann EP. Methods for improving the performance of silane coupling agents. J Adhes Sci Technol 1991; 5: 831-42.

19. Aksornmuang J, Nakajima M, Foxton RM, Tagami J. Regional bond strengths of a dual-cure resin core material to translucent quartz fiber post. Am J Dent 2006; 19: 51-5.

20. Aksornmuang J, Foxton RM, Nakajima M, Tagami J. Microtensile bond strength of a dual-cure resin core material to glass and quartz fibre posts. J Dent 2004; 32: 443-50.

21. Fernanda Tranchesi Sadek, Francesca Monticelli, Cecilia Goracci Franklin R. Tay, Paulo E.C. Cardoso, Marco Ferrari Bond strength performance of different resin composites used as core materials around fiber posts dental materials. 2007; 23: 95-9.

22. Gary Alex Universal Adhesives: The Next Evolution in Adhesive Dentistry? Compendium 2015; 36: 15-23. 